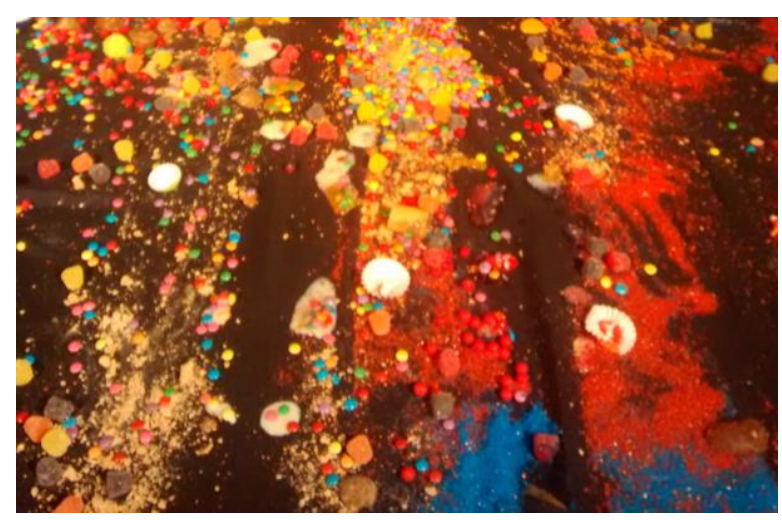

\title{
Sobre as performances Oblação, de Bia Figueiredo, e $A$ outra coleção particular de Stéfano Belo, de Stéfano Belo.
}

\author{
Sur les performances Oblation, de Bia Figueiredo, et L'autre collection particulière de \\ Stéfano Belo, de Stéfano Belo
}

Daniel Verginelli Galantin ${ }^{1}$

\begin{abstract}
Resumo:
Neste artigo propomos uma leitura das performances Oblação e A outra coleção particular de Stéfano Belo, de modo a propor um diálogo com certos elementos do pensamento de Gilles Deleuze e Félix Guattari. Neste caso, trabalharemos com os conceitos de corpo sem órgãos e a reflexão sobre o julgamento. Em menor grau, também dialogaremos com Michel Foucault e Franz Kafka. Nossa hipótese de leitura é que ambas as performances dizem respeito às formas de organização dos corpos e da subjetivação operantes no interior das sociedades capitalistas contemporâneas, assim como desenvolvem formas de resistências que não passam por qualquer tentativa de recuperação de elementos originários dos corpos. Em ambos os casos, trata-se de desorganizar as formas de corpos promovidas por regimes hegemônicos, e de experimentar formas de estar consigo e com os outros. Os escritos dos autores mencionados podem fornecer algumas indicações tanto para a crítica das subjetivações hegemônicas, quanto para a construção de formas de uma vida outra. Concluímos com a extensão dessa análise para diagnosticar parte do panorama político contemporâneo brasileiro, integrando assim as duas performances numa panorama ético-político mais amplo.
\end{abstract}

Palavras-chave: Deleuze. Guattari. Foucault. Performance. Ética. Política.

\section{Résumé:}

Dans cet article on propose une lecture des performances Oblação et A outra coleção particular de Stéfano Belo, de manière à proposer un dialogue avec certains éléments de la pensée de Gilles Deleuze et Felix Guattari. Dans ce cas, on travaillera avec les concepts de corps sans organes et la réfléxion sur le jugement. Dans une moindre mesure, on dialogera aussi avec Michel Foucault e Franz Kafka. Notre hypothèse est que les deux travaux remettent aux formes d'organization et de subjectivation en oeuvre à l'intérieur des sociétés capitalistes contemporaines. De la même façon, elles suggèrent des formes de résistence qui ne passent pas par l'essaie de rétablissement d'un élément originaire des corps. Dans les deux cas, il s'agit de la désorganisation des corps et des subjectivités produites par des régimes hégémoniques et d'expérimenter des nouvelles formes d'être avec soi et les autres. Les écrits des auteurs mentionnés peuvent fournire quelques indications et à la critique des subjctivations hégémoniques, et à la construction des formes de vie autre. On conclut avec l'exténsion de cette analyse pour diagnostiquer, en partie, le panorama politique brésilien contemporain, intégrant ainsi ces peformances dans un panorama éthico-politique plus élargit.

Mots-clés: Deleuze. Guattari. Foucault. Performance. Ethique. Politique.

\footnotetext{
${ }^{1}$ Bolsista de Pós-doutorado Júnior do CNPq na PUC-PR/CNPq Processo 167376/2017-9, e-mail: d.galantin@gmail.com, Orcid: https://orcid.org/0000-0003-3833-7955
} 


\section{Apresentação}

Este artigo se concentra em performances realizadas durante a IV edição da mostra "Transborda", concretizada sem qualquer financiamento externo e realizada no dia 28 de novembro de 2015. O recorte da curadoria incluiu predominantemente artistas que moram no espaço do Concentrado Artístico Água-viva. Assim, ocorreram performances de Stéfano Belo, Eduardo Colgan e Bia Figueiredo, com o acréscimo de trabalhos agregados de Luciano de Mesquita Faccini e Ricardx Nolascx. Estar concentrado é estar atento. Concentrar-se é estar junto, é ter centros em comum. O concentrado se dissolve e ainda é. E é mais. Bia Figueiredo, Félix Varejão, Gustavo Pinheiro, Luciano Faccini, Mariana Lopes, Renato Tortorella e Tamíris Spinelli se concentraram em 2013 com a intenção comum de produzir e explorar caminhos diversos da expressão artística audiovisual, musical, fotográfica, coreográfica, performática, imagética, ética, plástica, afetiva, política, sensorial, humana. Desde então, vêm realizando diversas ações artísticas.

\section{Um corpo-sem-órgãos para uma vida não-fascista}

Nossos corpos são cotidianamente perpassados por signos que visam incitar-lhes determinados comportamentos, favorecer ou dificultar e direcionar certos modos de agir, certos modos de fazer conexões com outros corpos e consigo mesmo. Alguns signos impõem padrões e cobram um esforço motivado por tristeza para seguir tais padrões; uma tristeza, porém, que não pode conduzir ao questionamento desses padrões, mas apenas ao esforço em alcança-los. Outros visam uma mobilização total dos corpos via uma competição acirrada em que os sucessos e fracassos são atribuídos única e exclusivamente aos competidores. Outros signos ainda visam criar novos comportamentos, inventar modos de vida a serem adotados e transformados pelos corpos, de modo que tais signos são flexíveis o suficiente para serem incorporados e transformados (ou mesmo exigem-no) através de modos de se vestir, de transar, de gozar, de criar identidades de gênero, de se relacionar com os objetos, de avaliar outros corpos e outros modos de vida, de avaliar a si mesmo. Mesmo a arquitetura atravessa nossos corpos, com sua segmentação de espaços e formas que podem favorecer determinados usos do espaço e dificultar outros, e, da mesma maneira, facilitar ou dificultar certos modos de viver. 
Um único signo poderia atuar simultaneamente em todas estas dimensões, de modo que devemos pensar que nossos corpos são atravessados e transformados por um complexo e múltiplo ciclo de mercado, de consumo, produção e circulação. Contudo esta circulação não funciona apenas através da transmissão de informações para sujeitos dados com seus corpos dados. Ela transforma nossos corpos ao transpassá-los, exigindo que eles se transformem também em máquinas de produção e emissão de tais signos. Enfim, todo este regime acaba por organizar nossos corpos quanto ao sentido mais radical do termo: eles fazem dos corpos organismos.

As performances Oblação, de Bia Figueiredo, assim como a A outra coleção particular de Stéfano Belo, de Stéfano Belo, trabalham fundamentalmente este eixo que liga corpo, comunicação e subjetividade. Em Oblação, Bia expõe seu próprio corpo nu enquanto oferenda a ser consumida pelo público através dos doces que lhe ornamentam. Ao fundo escutamos uma gravação: “Oferenda; objeto a ser moldado; corpo recipiente; corpo vazio. Me oferenda. Latino americano embalado. Corpo sendo vigiado. Alvo de consumo. Corpo enclausurado em seus privilégios, mediado pela publicidade" Um corpo que já é cotidianamente colocado em circulação e atravessado por diversos regimes, como o médico, o pornográfico, a moda, o transporte, os espaços que ele habita, finalmente torna-se uma oferenda; uma oblação que nos faz pensar sobre nossos próprios corpos. A outra coleção particular de Stéfano Belo foi composta de 3 atos, de modo que daremos destaque a um deles na medida em que parece dialogar diretamente com o tema do corpo. No ato intermediário, Stéfano performa uma dança, em meio ao público, com a manipulação da gordura corporal própria, enquanto ao fundo escutamos a reprodução de uma leitura de $O$ artista da fome, de Kafka. A oposição entre o corpo do faquir e o corpo do performer é apenas aparente, pois ambos os corpos não cabem no regime de seu contexto, estão em excesso. Com as duas performances podemos estabelecer dois eixos de questionamento: 1) Nós não temos um corpo substancial que ganha ou perde atributos, mas sim inumeráveis corpos possíveis, muitos dos quais se encontram para além do campo da possibilidade, ao menos se compreendermos que são estes regimes que delimitam nossas possibilidades, e, ao mesmo tempo, que esses mesmos regimes não são necessários ou eternos. 2) Os atuais regimes de fluxo de signos, guiados pelo mercado, são produtores de pobreza em modos de viver, de pobreza de possíveis. Sabemos que, hoje, a publicidade não se foca exclusivamente nos atributos dos produtos, mas nos modos de vida que estão vinculados a estes produtos, e 
que criam novas demandas - hoje, junto com produtos, consumimos subjetividade. Mas quantos modos de viver efetivamente diferentes são oferecidos pelo mercado? Nossa pobreza em modos de vida, ironicamente, parece ser inversamente proporcional à miríade de diferentes tipos de um mesmo produto disponível no mercado.

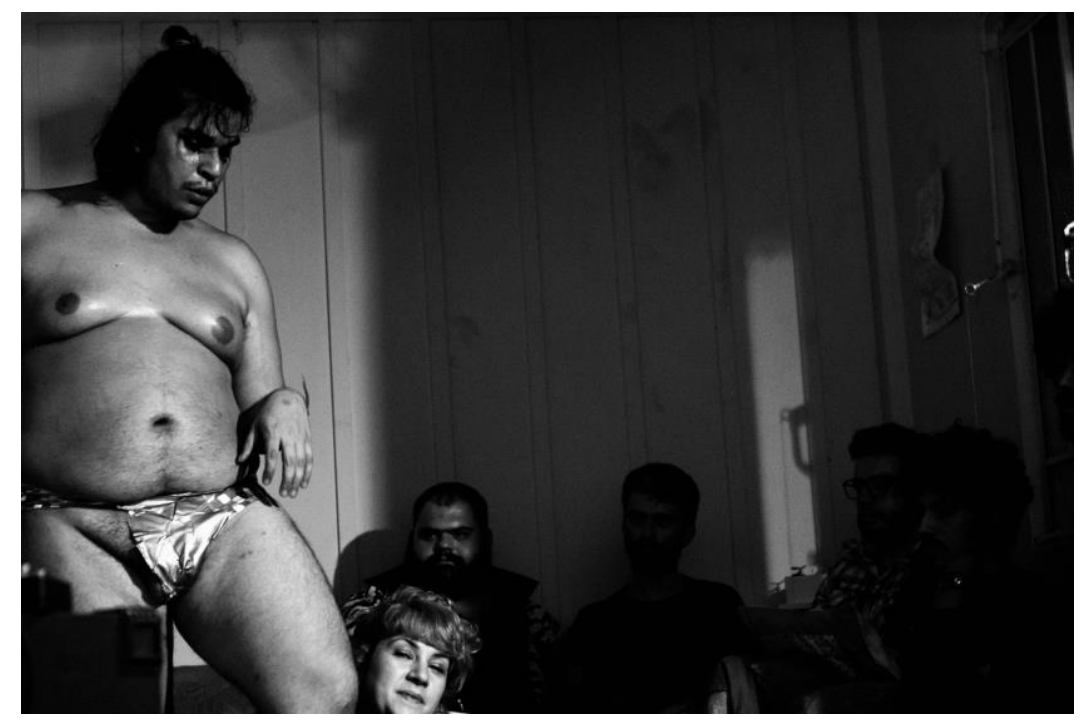

* Foto de A outra coleção particular de Stéfano Belo (foto de Mariama Lopes)

A partir disso, podemos dizer que nenhuma das duas performances se restringe a nos apresentar um corpo-signo que interpreta a condição do corpo na contemporaneidade. Em Oblação, o fato de haver uma interação praticamente obrigatória com o corpo da performer nos coloca diante de um convite para uma experiência com relação a nossos próprios corpos, pois eles também estão em jogo ali. Contudo, eles não estão ali como um referente do qual se fala a partir de uma troca entre pares simétricos, mas como um convite a uma experiência. Mesmo quando estamos diante de algo incontornável a todos os corpos, como a finitude, como o fato de que aquele corpo pode e vai um dia morrer, mas também o fato dele sofrer por calor ou frio, passar dores, incômodos de todos os tipos; mesmo quando fica evidente que aquele corpo tem limites, nossos corpos estão inevitavelmente implicados nele. Porém, essa implicação não é aquela em que nos reconhecermos nele como num alter ego, mas do tipo em que a exposição de um corpo aos seus limites coloca os nossos à prova. Neste sentido, A outra coleção particular de Stéfano Belo provoca o mesmo movimento de inquietação, com uma interação com o público mais controlada pelo artista. 
Em Oblação, aquele corpo exposto enquanto uma oferenda ao consumo, ao jogar com seus limites e com os nossos limites, ao invocar sua inserção num ciclo de produção e consumo que nos atravessa e nos constitui, é um convite à desorganização de nossos corpos. Contudo, é preciso ressaltar que os regimes de produção e incorporação de signos aos quais nos referimos, e que passam pelo mercado, parecem concentrar-se muito mais na produção que no consumo. Hoje não consumimos mais como o fogo consome, ou como o potlatch na forma de prestações agonísticas das tribos estudadas por Mauss em seu Ensaio sobre a dádiva (MAUSS, 2003, p.191-193). Hoje, os signos que nos mobilizam subsumem o consumo à produção, pois se trata de produzir um corpo que sustente tal regime, que possa circular, que saiba habitar os espaços que lhes são oferecidos, que transe e goze de modo proveitoso a estes regimes (ou ao menos que não os incomode). Enfim, um corpo que respeite os limites estabelecidos por tais regimes e que, quando se engajar em transformá-los, que possa ser de modo tal que as transformações possam ser capitalizadas. Se tais regimes são aquilo que nos faz sujeitos, coloca-los em jogo é também fazer dos corpos um espaço de experiência que diz respeito à possibilidade de deixarmos de ser sujeitos. Evidentemente isso não pode ser feito sem colocarmos a nós mesmos, também, em jogo. Não se trata, com isso, de reencontrarmos nosso verdadeiro eu para além de um limite onde estaria a terra prometida da liberdade, mas de abandonarmos a nós mesmos num espaço de errância onde, ao invés de liberdades, encontramos apenas saídas. Neste caso, deixar de ser sujeito, corporalmente, é o mesmo que desorganizar-se, desorganizar o corpo cujo organismo é constituído pelos regimes que mencionamos muito rapidamente. Apenas com semelhante desorganização poderíamos construir um corpo outro. No caso de Oblação, podemos perguntar-nos que tipo de conexão poderíamos fazer com o corpo da performer, e que se constituísse como uma dissidência para com os regimes de sujeição que ela busca colocar em jogo? Qual outra conexão conosco mesmos poderíamos construir em decorrência dessa outra interação com o corpo dela? Todo o desafio éticopolítico da performance de Bia estaria, talvez, nesse conjunto de questões.

Como criar um corpo sem órgãos ( $\mathrm{CsO})$ para si mesmo? É a questão que Deleuze e Guattari fizeram, a partir de Antonin Artaud, na terceira parte de Mil Platôs, sobre a possibilidade de deixarmos de ser sujeitos. As duas performances parecem explorar este território, cada uma delas à sua maneira: 
Você será organizado, você será organismo, articulará seu corpo senão você será um depravado. Você será significante e significado, intérprete e interpretado - senão será desviante. Você será sujeito e, como tal, fixado, sujeito de enunciação rebatido sobre um sujeito de enunciado - senão você será apenas um vagabundo. Ao conjunto dos estratos, o $\mathrm{CsO}$ opõe a desarticulação (ou as $n$ articulações) como propriedade do plano de consistência, a experimentação como operação sobre este plano (nada de significante, não interprete nunca!), o nomadismo como movimento (inclusive no mesmo lugar, ande, não pare de andar, viagem imóvel, dessubjetivação) (DELEUZE; GUATTARI, 2008, p. 22).

No entanto, desorganizar nossos corpos, produzir um corpo sem órgãos, não é fácil e nem isento de perigos. Tratando-se de uma experiência, há sempre um risco inerente a todo $\mathrm{CsO}$, como se o perigo que está na própria raiz da palavra experiência sempre batesse à porta. Deleuze e Guattari apontaram alguns desses perigos: os CsO fascistas e totalitários - apenas lembremos que o nazismo não nasceu da organização dos estratos estatais, mas de grupos que atuavam na clandestinidade e fora do Estado; os CsO vazios, como o corpo da overdose, do paranoico, do hipocondríaco. Donde podemos nos perguntar: como ter certeza de que não teremos um $\mathrm{CsO}$ fascista, ou vazio? Para isso seria preciso um modelo geral do $\mathrm{CsO}$, o qual serviria de critério regulador, o que equivale a encontrar sua estrutura universal, ainda que vazia de conteúdo. Essa resposta é semelhante àquela encontrada em praticamente todos os movimentos políticos de contestação quando estes se tornam demasiadamente unitários, ávidos em acabar com dissidências ou em se auto-afirmar diante de outros como os arautos da resistência, portadores da verdadeira teoria e prática. Esse movimento se equivale, em termos corporais, à organização do $\mathrm{CsO}$, ou ainda, ao juízo de Deus, que desencadeia a organização:

O CsO não se opõe aos órgãos, mas, com seus 'órgãos verdadeiros' que devem ser compostos e colocados, ele se opõe ao organismo, à organização orgânica dos órgãos. O juízo de Deus, o sistema do juízo de Deus, o sistema teológico, é precisamente a operação Daquele que faz um organismo, uma organização de órgãos que se chama organismo porque Ele não pode suportar o $\mathrm{CsO}$, porque Ele o persegue, aniquila para passar antes e fazer passar antes o organismo (DELEUZE; GUATTARI, 2008, p. 21).

Nossa única arma para contornar tanto o juízo de Deus (que deve ser entendido não somente no âmbito teológico, mas num plano geral de subsunção da multiplicidade à unidade), quanto para evitar criar $\mathrm{CsO}$ fascistas e de autodestruição, pode ser definida 
como uma espécie de prudência; a prudência da arte das doses para evitar a overdose, por exemplo. Logo, diferentemente de uma tradição filosófica que pensa a prudências nos termos de um bom uso da razão, Deleuze parece pensá-la nos termos de um bom uso da desorganização e da experimentação ${ }^{2}$. Esta prudência caracteriza-se justamente por não se embasar numa teoria geral orientadora da ação, mas sim num posicionamento estratégico, eminentemente instável e sempre pronto para transformar-se de acordo com as mudanças circunstanciais. Uma estratégia que esteja sempre apta a se dissolver. Isso significa que, para que uma estratégia seja forte, será necessário que se tenha um enorme conhecimento da situação na qual nos encontramos, da constituição do campo de batalha, e das forças a serem combatidas e de como elas se afetam e se transformam a todo momento; em resumo, um conhecimento das circunstâncias.

Isso porque o $\mathrm{CsO}$ não para de oscilar entre as superfícies que o estratificam e o plano que o libera. Liberem-no com um gesto demasiado violento, façam saltar os estratos sem prudência e vocês mesmos se matarão, encravados num buraco negro, ou mesmo envolvidos numa catástrofe, ao invés de traçar o plano. O pior não é permanecer estratificado - organizado, significado, sujeitado - mas precipitar os estratos numa queda suicida ou demente, que os faz recair sobre nós, mais pesados do que nunca. Eis então o que seria necessário fazer: instalar-se num estrato, experimentar as oportunidades que ele nos oferece, buscar aí um lugar favorável, eventuais movimentos de desterritorialização, linhas de fuga possíveis, vivenciá-las, assegurar aqui e ali conjunções de fluxos, experimentar segmento por segmento dos contínuos de intensidades, ter sempre um pequeno pedaço de uma terra nova (DELEUZE; GUATTARI, 2008, p. 23-24).

Talvez, o post-porn ${ }^{3}$ de artistas como Annie Sprinckle e Cheryl Dunye ou a pornografia feminista de Erika Lust podem ter aspectos dessa luta estratégica. Pois elas divergem da pornografia tradicional, contudo, sem cair na vitimização daqueles em jogo (posição que esvazia a capacidade de ação dos agentes); sem resvalar num apelo à moral, que se horroriza quando o trabalho chega na genitália, uma das crias mais arcaicas do juízo de Deus; sem reproduzir o roteiro da pornografia feita por homens

\footnotetext{
2 Apesar do texto de Deleuze referir-se a um quadro de pensamento mais amplo que o kantismo, poderíamos pensar, por exemplo, como os juízos kantianos se dão no quadro de uma subjetividade transcendental, enquanto que, em Deleuze, aquilo que está em questão é um movimento de dessubjetivação conconcomitantemente à construção de uma outra forma de subjetividade, um outro arranjo entre forças. Querer julgar a priori ou a posteriori esse novo arranjo apenas pode ser feito mediante a conservação da unidade subjetiva, mas experimentar essa nova configuração implica numa transformação de si mesmo avessa a esse tipo de juízo. Na nota 5 mais ao final, veremos que Deleuze não parece descartar toda e qualquer forma de separação entre existentes.

${ }^{3}$ Sobre o post-porn, ver o artigo de Marie-Hélène Bourcier (BOURCIER, 2014).
} 
para homens. Neste tipo de manifestação cultural, as tradicionais imagens e sequências da pornografia passam por um curto-circuito que as faz circular de uma maneira diversa; ao mesmo tempo, novos possíveis de corpos e prazeres podem vir a articular-se nesse pequeno espaço aberto. De toda maneira, talvez este seja um dos planos que nos são abertos pela interrogação lançada pela performance Oblação: não a crítica ao consumo ou à objetificação, com restos de leis morais ao fundo e uma escatologia de promessa de desalienação futura. Liberar "o corpo" ainda é desalinear uma essência, e sair da posição de objeto para a de sujeito só é possível a partir de uma sujeição em que os termos se invertem, mas seus atributos são conservados. Oblação parece nos convidar antes para uma experiência de nossos corpos, uma outra conexão para com nosso corpo, um consumo diverso e outras conexões com os corpos dos outros, de modo tal que os fluxos de signos e de sentidos que organizam nossos corpos sejam interrompidos. Podemos dizer que se trata de fazer com nossos corpos aquilo que a literatura moderna fez com a linguagem. Em A loucura, a ausência de obra, artigo de 1964, Foucault escreveu que a literatura moderna "supunha sob cada uma de suas frases, sob cada uma de suas palavras, o poder de modificar soberanamente os valores e as significações da língua à qual, apesar de tudo (e de fato), ela pertencia; ela suspendia o reino da língua num gesto atual de escritura" (FOUCAULT, 2001a, p. 446-447). Ao jogar com a ideia de consumo, a performance de Bia, de modo análogo, nos convida a suspender a organização de nossos corpos, fazendo da apresentação uma experiência da qual saímos estranhos a nós mesmos.

A outra coleção particular de Stéfano Belo, de Stéfano Belo, também parece lidar com a construção estratégica de um $\mathrm{CsO}$. Ao incorporar trechos de $O$ artista da fome, de Kafka, no meio de uma apresentação que explora as possibilidades que a gordura corporal oferece, para além de sua classificação médico-moral enquanto obesidade, o performer nos sugere uma eminente comparação entre o corpo do faquir que jejua com o corpo do performer. Ambos são corpos que estão num eminente combate ou jogo com seus próprios limites, o corpo do faquir que sempre quer jejuar mais e mais, e o corpo do performer, o qual se aventura num processo de moldar a si mesmo de uma forma diversa dos regimes de signos que mencionamos, e diverso da forma como nós mesmos olhamos para ele a partir desses signos. Aqui o próprio corpo do performer parece entrar num combate com os fluxos de signos que o atravessam, de modo que o combate é também combate para consigo mesmo; como se o corpo do 
performer estivesse engajado num processo em que ele cria formas diferentes daquelas que são visadas pelos fluxos; como se ele inserisse códigos desviantes em meio a estes fluxos. Ao remodelar seu corpo, Stéfano busca remodelar nosso próprio olhar. Assim como o faquir quer jejuar sempre cada vez mais e jogar com seus limites, o performer também está sempre se aventurando na criação de formas corporais errantes e irredutíveis, pois nenhum regime oferecido pode lhe saciar.

Poderíamos ainda articular estes corpos ou estas experiências corporais com aquele do acrobata de Um artista do trapézio. Nesta historieta somos apresentados a um trapezista que passa a viver apenas nas alturas, buscando ficar cada vez mais tempo pendurado, acrescentando sempre um trapézio a mais. Todos esses corpos parecem estar colocando à prova os seus limites ao desorganizarem-se, e, por isso, causam tanto incômodo. E nada disso diz respeito a uma decisão ou projetos subjetivos, pois como diz o faquir nos ouvidos do inspetor ao final do conto de Kafka, ele não jejua porque assim o quer, mas porque não pode evitá-lo: "porque não pude encontrar comida que me agradasse. Se a tivesse encontrado, pode acreditar, não teria feito nenhum alarde e me empanturrado como você e todo mundo" (KAFKA, 2000, p.19). Fazer um CsO para si não está relacionado ao voluntarismo de um sujeito, como se tratasse da faculdade de vontade de um sujeito, mas com a dimensão da vontade que escapa ao seu poder enquanto sujeito ${ }^{4}$; aquilo que nele, mesmo enquanto sujeito, ainda pode jogá-lo para fora de si mesmo - talvez algo como uma decisão não-subjetiva, espaço em que a falta coincide com o excesso. Diante de tal possibilidade, contudo, é preciso ter prudência para evitar os $\mathrm{CsO}$ que nos precipitam no abismo ao invés de nos ensinar a caminhar na sua beirada, a dançar equilibrados nos seus limites.

Deleuze escreverá, também a partir de Artaud, que acabar com o juízo de Deus implica que o corpo entre numa relação de combate consigo mesmo. Talvez possamos dizer que se trata do mesmo tipo de combate para o qual as duas performances nos desafiam. Se o juízo cria instâncias transcendentes de mediação, o combate diz respeito apenas à justiça e à imanência:

\footnotetext{
${ }^{4}$ Neste sentido, podemos notar como o texto de Deleuze, em Crítica e Clínica, parece retomar a reflexão mais antiga de Nietzsche e a filosofia (DELEUZE, 2014, p.78) sobre a vontade de poder nietzschiana, que ele traduz como vontade de potência. A única dimensão de voluntarismo que poderíamos admitir para a construção de um $\mathrm{CsO}$ seria ao pensarmos a vontade nos termos da leitura deleuziana da vontade de potência nietzschiana, isto é, como unidade apenas enquanto palavra e sempre em excesso com relação aos limites da unidade subjetiva.
} 
combate, por toda parte combate, o combate substitui o juízo. Sem dúvida o combate aparece contra o juízo, contra suas instâncias e seus personagens. Porém, mais profundamente, o próprio combatente é combate, entre suas próprias partes, entre as forças que se subjugam ou são subjugadas, entre as potências que exprimem essas relações de força (DELEUZE, 1997, p. 149).

As performances de Bia Figueiredo e Stéfano Belo, por sua vez, nos convidam, ou melhor, nos desafiam a pensar como construir um $\mathrm{CsO}$ para nós hoje. E para tal, é preciso que entremos em combate para com as instâncias do julgamento de Deus que organizam nossos corpos e, ao mesmo, que entremos em combate para com nósmesmos, nós, que somos atravessados tanto pela organização do juízo que nos confere identidades, quanto povoados por $\mathrm{CsO}$ totalitários e vazios. Novamente, precisamos lembrar que o desafio é construir um $\mathrm{CsO}$ e não $o \mathrm{CsO}$. Para construir um $\mathrm{CsO}$ não podemos nos apoiar nas certezas e parâmetros de um modelo com validade para todos em qualquer lugar, o que significa não haver regra universal a ser encontrada. Reconhecer a impossibilidade de contar com um fundamento não significa aceitar a chantagem de que, então, nos resta apenas algo como uma equivalência geral entre tudo. Significa enfrentar a urgência de criação de um novo modo de avaliar, em que avaliar e experimentar andem de mãos dadas. Novamente dirá Deleuze:

O que nos incomodava era que, renunciando ao juízo, tínhamos a impressão de nos privarmos de qualquer meio para estabelecer diferenças entre existentes, entre modos de existência, como se aí tudo se equivalesse. Mas não é antes o juízo que supõe critérios preexistentes (valores superiores), e preexistentes desde sempre (no infinito do tempo), de tal maneira que não consegue apreender o que há de novo num existente, nem sequer pressentir a criação de um modo de existência? Um modo de existência se cria vitalmente, através do combate, na insônia do sono, não sem certa crueldade contra si mesmo: nada disso tudo resulta do juízo. O juízo impede a chegada de qualquer modo de existência. Pois este se cria por suas próprias forças, isto é, pelas forças que sabe captar, e vale por si mesmo, na medida em que faz existir a nova combinação. Talvez esteja aí o segredo: fazer existir, não julgar. Se julgar é tão repugnante, não é porque tudo se equivale, mas ao contrário, porque tudo o que vale só pode se fazer e distinguir-se desafiando o juízo. Qual juízo perito, em arte, poderia incidir sobre a obra futura? Não temos que julgar os demais existentes, mas sentir ${ }^{5}$ se eles nos convêm ou desconvêm, isto é, se nos trazem forças ou então nos remetem às

\footnotetext{
${ }^{5}$ Neste caso, podemos notar como Deleuze não está abolindo todo e qualquer juízo, mas trazendo em cena a possibilidade de outra forma de pensar, em que separar aquilo que convém daquilo que não convém diria respeito a uma forma de experimentação. É possível que, neste caso, o esforço de Deleuze em construir um empirismo transcendental se conecte à construção dessa nova forma de sensibilidade em que não se trata de estabelecer juízos anteriores ou posteriores à experiência, mas à própria experiência como movimento transformação de si mesmo e, logo, do julgamento.
} 
misérias da guerra, às pobrezas do sonho, aos rigores da organização

(DELEUZE, 1993, p. 168-169).

Talvez estejamos diante de uma questão um pouco mais ampla. Essa questão poderia ser formulada mais ou menos nos termos de Michel Foucault ao escrever sobre Deleuze e Guattari: como criar uma vida não-fascista? (FOUCAULT, 2001b, pp.133136). Novamente, vejamos que se trata de uma vida, e não da vida. Se não há fórmula para isso, certamente ao menos precisamos ter muita atenção para com aquilo que se passa em nosso presente, e, segundo Deleuze e Guatarri, uma boa dose de prudência para nos ajudar na construção de uma estratégia forte:

É necessário guardar o suficiente do organismo para que ele se recomponha a cada aurora; é também necessário conservar pequenas provisões de significância e de interpretação, inclusive para opô-las ao seu próprio sistema, quando as circunstâncias o exigem, quando as coisas, as pessoas, inclusive as situações nos obrigam; e é preciso conservar suficientemente pequenas rações de subjetividade para poder responder à realidade dominante. Imitem os estratos. Não se atinge o CsO e seu plano de consistência desestratificando grosseiramente (DELEUZE; GUATTARI, 2008, p. 23).

\section{Conclusão}

Para concluir, gostaríamos de propor ainda uma observação acerca de Oblação e A outra coleção particular de Stéfano Belo. Em primeiro lugar, podemos dizer, resumidamente, que as duas performances nos apresentam um corpo ético-político, e nos lembram que nossos próprios corpos são, eles também, ético-políticos. Elas nos mostram que a política não é apenas aquela atividade entre homens e mulheres, que se desenvolve num espaço público bem delimitado e mediado por instituições, mas que nossos próprios corpos já são intrinsecamente políticos, atravessados por regimes políticos. Justamente por isso, esses corpos são também um espaço possível de resistência, a qual não pode ser pensada sem uma ética. Essa ética, contudo, não é pensada nos termos de uma lei moral, mas como relação de transformação imanente para consigo mesmo e com os outros. Na performance de Stéfano, o movimento de dar forma a si mesmo, manipulando a gordura corporal, confere outro sentido à normalidade dos corpos. O combate contra o juízo organizador da normalidade se dá concomitantemente a um combate entre si mesmo do performer. $\mathrm{O}$ afrontamento em cena não é uma simples oposição que nega a normalidade, mas um desvio, uma transformação do próprio corpo numa obra de arte. A auto-oferenda de Bia é um convite tanto a uma reflexão e uma experiência sobre nossas relações de gênero e as 
micropolíticas que sustentam uma realidade patriarcal, quanto sobre possiblidades outras de corpos e de prazeres, o que também incita ao combate conosco mesmos. Ambas as performances carregam um forte teor crítico. Contudo, não remetem a uma crítica que se dê a partir de uma posição transcendental, mas sim imanente. Uma crítica que, antes de julgar, faz existir, de modo que a crítica se torna um permanente trabalho de nós sobre nós mesmos, embate permanente entre nossas partes, escapando dos os juízos que querem nos organizar de uma vez por todas, e dos microfascismos que nos povoam.

Em segundo lugar, podemos dizer que há todo um vocabulário no escrito sobre o $\mathrm{CsO}$ que pode dar vazão a leituras que o definiriam como um grande acontecimento, visível a todos, reconhecível como a alma da revolta e a resistência absoluta. Isso se dá através de leituras heroicizantes, que nada mais são que signo de organização, já que todo heroísmo propõe, de certa maneira, um modelo válido para todos e em todos os lugares. Porém, um $\mathrm{CsO}$, ou mais amplamente, um movimento de dessubjetivação, pode passar pela dimensão mais sutil de um corpo, como sua sombra. No caso, pensamos que a sombra formada pela saída do corpo de Bia após o término da performance pode ser sugestiva. Uma sombra geralmente remete a uma ausência que, por sua vez, designa uma presença: toda sombra só existe porque algo está presente interrompendo a luz; ela dá os contornos daquilo que não podemos ver quando a olhamos. Mas esse não é esse o caso da sombra que gostaríamos de mencionar. Talvez hajam sombras cuja autonomia parece indicar não apenas a ausência do corpo que lhe servia de molde, mas sombras que seriam, simultaneamente, uma presença e uma ausência. Essa presença ausente pode ainda ser um corpo com todas as suas forças. Não um corpo determinado de alguém, com uma identidade reconhecível, um gênero atribuído, um espaço delimitado, uma sexualidade definida, uma etnia, uma língua, uma História comum. Mas também não se trata, neste caso, de um corpo universal, portador de todas as propriedades que todos, em todos os tempos e lugares têm em comum, mas um corpo de qualquer um.

Há uma dimensão de qualquer um em todos nós que muitas vezes não temos sensibilidade ou coragem para explorar. Trata-se de uma dimensão que pensadores como Blanchot exploraram a fundo na linguagem, com figuras como o impessoal e o neutro:

(...) o que pertence ao neutro não é um terceiro gênero que se opõe aos dois outros e constituindo uma classe determinada de existentes ou de seres de razão. O neutro é aquilo que não se distribui em gênero 
algum: o não-geral, o não-genérico, como o não-particular. Ele recusa o pertencimento tanto à categoria de objeto quanto à de sujeito. E isso não quer apenas dizer que ele ainda é indeterminado e hesitante entre ambos, mas quer dizer que ele supõe uma relação outra, não dependendo de condições objetivas, nem de disposições subjetivas (BLANCHOT, 2009, p. 440).

Blanchot e Deleuze nos ajudam a perceber que a dimensão de qualquer um não significa um atributo universal de todos os corpos particulares, mas uma multiplicidade que resulta da desorganização: “Assim, o corpo sem órgãos nunca é o seu, o meu... É sempre um corpo (...): Ao artigo indefinido nada falta, ele não é indeterminado ou indiferenciado, mas exprime a pura determinação de intensidade, a diferença intensiva" (DELEUZE; GUATTARI, 2008, p.28). Ao invés do eixo universal-particular, qualquer um nos remete ao plano da multiplicidade-singularidade. Qualquer um poderia ser como a sombra de um corpo, o indicador que, mesmo enquanto sujeitos, nós nunca estamos totalmente organizados, que sempre há uma possibilidade de deixarmos de ser nós mesmos. Ali onde o mercado ou os técnicos da subjetividade dizem que precisamos encontrar nosso eu, ou quando a publicidade diz que nosso eu se completa quando adotamos não apenas seus produtos, mas também seus modos de viver, ambas as performances da mostra Transborda parecem dizer: "vamos mais longe, não encontramos ainda nosso $\mathrm{CsO}$, não desfizemos ainda suficientemente nosso eu. Substituir a anamnese pelo esquecimento, a interpretação pela experimentação" (DELEUZE; GUATTARI, 2008, p.11). Na atualidade, o recrudescimento dos identitarismos mais fortes na esquerda ${ }^{6}$ e na direita, aliados à incansável venda de modos de vida que povoam de out-doors a programas de reality show, parecem confirmar a urgência dessas performances como parte de um esforço coletivo para pensar e construir dissidências dentro de nós mesmos.

Hoje, pouco mais de 2 anos após a Transborda de 2015, muitos indícios confirmam um avanço reacionário no país, que nos inquietava desde então. Mas para entender esse movimento de reação, visando resataurar um estado anterior de coisas, é preciso evitar a metáfora do caminho de mão dupla que comunica dois lugares, um à frente e outro atrás. Para reagir a uma mudança, os conservadores devem avançar em outra direção. Ademais, precisamos estar atentos tanto às especificidades da realidade brasileira, quanto àquilo que a insere em movimentos que vão além de suas fronteiras.

\footnotetext{
${ }^{6}$ Sobre isso chamo atenção para o artigo de Richard Miskolci "Notas sobre os microfascismos nas redes sociais" (MISKOLCI, 2017) em que a subjetivação neoliberal é destacada como operadora dentro de vários movimentos de contestação.
} 
Ao que parece, estamos diante de uma reorganização de forças, de acoplamentos entre aquilo que há de mais arcaico em nosso cotidiano, como a manutenção de privilégios regulamentados e tácitos, os ecos da escravidão, e aquilo que há de novo num mundo globalizado, atravessado por redes e fluxos, de capital e informações. O racismo diz respeito tanto ao nosso passado escravocrata, mas também a dispositivos securitários extremamente novos e a uma polícia que não se reformou com a redemocratização de 1984. A homofobia e a transfobia dizem respeito a uma cultura católica, mas também aos fenômenos neopentencostais e ao eugenismo do século XIX (essa proveniência ela compartilha com o racismo), o qual muito pouco se admite abertamente fazer parte de nossa história. Os novos movimentos que defendem o fim de direitos sociais e da função redistributiva do Estado, também assumem um conservadorismo seletivo de costumes - quanto a isso, um breve olhar para a história do Brasil e da América Latina mostra como não há nada de novo nessa novidade. Talvez o recente ataque a determinadas formas de arte (notadamente em Brasília, São Paulo e Porto Alegre) não seja apenas uma cortina de fumaça, visando encobrir as reformas anti-democráticas levadas a cabo atualmente. Talvez esses ataques visem muito mais fomentar uma vida e um corpo conforme a esse tipo de política - lembremos que todas as artes atacadas trabalhavam com o corpo, DNA de DAN, de Maikon K, o Queer Museu, e La Bête, de Wagner Schwartz.

Hoje estão em formação novos $\mathrm{CsO}$ totalitários, outros que falam a língua da liberdade do mercado, e eles muito provavelmente procurarão se estratificar de alguma maneira, visando organizar novos corpos. Hoje os microfascismos colonizaram o Estado brasileiro após uma nova forma de golpe, e passam a promover certas políticas públicas e desmontar outras. Hoje, sob outras formas, uma lógica microfascista arrisca a se espalhar para os movimentos de contestação social fazendo deles o lugar de promoção de identidades as mais rígidas, formando um ambiente sectário. Em alguns casos, o ativismo tornou-se uma prática de auto-afirmação narcísica individual ou coletiva, e de rebaixamento dos outros ativistas, encarados como competidores por reconhecimento nas redes e pela última palavra sobre um problema ${ }^{7}$. Se hoje vivemos

\footnotetext{
${ }^{7}$ Neste caso valeria retomar a fundo um princípio sugerido por Foucault para a construção de uma arte de vida não-fascista: "não utilizem o pensamento para dar o valor de verdade a uma prática política; nem a ação política para descreditar um pensamento, como se esse fosse pura especulação. Utilizem a prática política como um intensificador do pensamento, e a análise como um multiplicador de formas e domínios de intervenção da ação política" (FOUCAULT, 2001b, p. 135),
} 
em estado de guerra $^{8}$, parte dos movimentos de contestação beiram reproduzir essa guerra em sua lógica de atuação, disputando a autoridade de uma fala incontestável, criando um clima de vigilância coletiva e multiplicando os julgamentos. Com isso, corremos o risco de perder aquilo que seria o mais potente destes movimentos, isto é, sua capacidade de invenção de novas formas de vida: a experimentação perder espaço para o julgamento. No mesmo texto sobre o julgamento, Deleuze chamou atenção sobre como o combate entre si, que, de nosso lado, encontramos nas duas performances da Transborda de 2015, é avesso à guerra, por sua vez pensada nos termos de combate contra o Outro:

É preciso distinguir o combate contra o Outro e o combate entre Si. O combate-contra busca destruir ou afastar uma força (lutar contra 'as potências diabólicas do porvir'), mas o combate-entre busca, pelo contrário, se apoderar de uma força para fazê-la sua. O combate entre é o processo pelo qual uma força se enriquece ao se apoderar de outras forças, ao juntar-se a ela num novo conjunto, num devir (DELEUZE, 1993, p.165).

Atualmente, episódios insurrecionais como os de 2013 correm o risco de se tornar objeto morto de adoração. A progressiva captura de um episódio insurrecionário que colocou a grande mídia e o estado de joelhos, pode ser esquecida em prol da promessa de seu retorno messiânico. Como pautas reivindicatórias de melhorias de serviços públicos, um humor sem precedentes nas palavras de ordem, e uma vontade de transformação radical do viver em comum, pôde, aos poucos, dar lugar a pautas reacionárias (obviamente, não em manifestações convocadas pelos mesmos grupos), e uma atitude hostil contra apenas uma fração do governo? A mídia (força que não é parte do Estado) teve um papel fundamental para isso, notadamente quando inventou a divisão entre manifestantes de bem e vândalos. Mas seriam eles os principais atores de tamanha mudança nos afetos coletivos? Alguns insistem que não devemos querer ocupar o Estado, como se ele fosse o verdadeiro inimigo a ser combatido, reproduzindo a concepção segundo a qual ele seria o centro irradiador de todo poder, com a única diferença que, ao invés de ocupado por uma classe ou partido, ele deve ser destruído ou destituído. Mas será que essa é realmente a questão? A ocupação do Estado pelos microfascismos novos e velhos não é sinal de que seu lugar, embora não central, ainda é estratégico? Se, por um lado, a ascensão desses microfascismos ao Estado foi fundamental para a destruição de direitos conquistados a duras penas, por outro lado,

\footnotetext{
${ }^{8}$ Sobre isso ver o texto de Peter Pál Pelbart, "Estamos em guerra” (PELBART, 2017).
} 
estes mircofascismos foram promovidos e fomentados a despeito do Estado, fora dele e, até certo ponto, contra ele (contra uma forma dele, contra algumas de suas políticas). Mais uma vez, é inegável a importância da grande mídia nacional para a formação e fomento desses mircofascismos, assim como para a criação e expansão de grupos de uma direita virulenta, dentro e fora das redes sociais, ensejando a formação do novo cenário de guerra. Contudo, no enfrentamento a esses microfascismos, é preciso cuidado para não reproduzirmos uma forma de unidade de ação igual àquela que eles promovem, não promover os mesmos afetos, mas inventar uma forma de coalizão que preserve uma tensão interna de forças sem que elas entrem em guerra umas contra as outras pelo domínio umas das outras. Neste sentido, talvez mais importante que insistir em abandonar o Estado, seja promover vidas não fascistas em todos os espaços políticos e politizáveis, dentro e fora das esferas políticas tradicionais, de modo a trazer novamente em cena a resistência política nos termos de fazer existir, e não nos termos do julgamento. As duas performances da Transborda de 2015 parecem já nos ter dado pistas desse movimento.

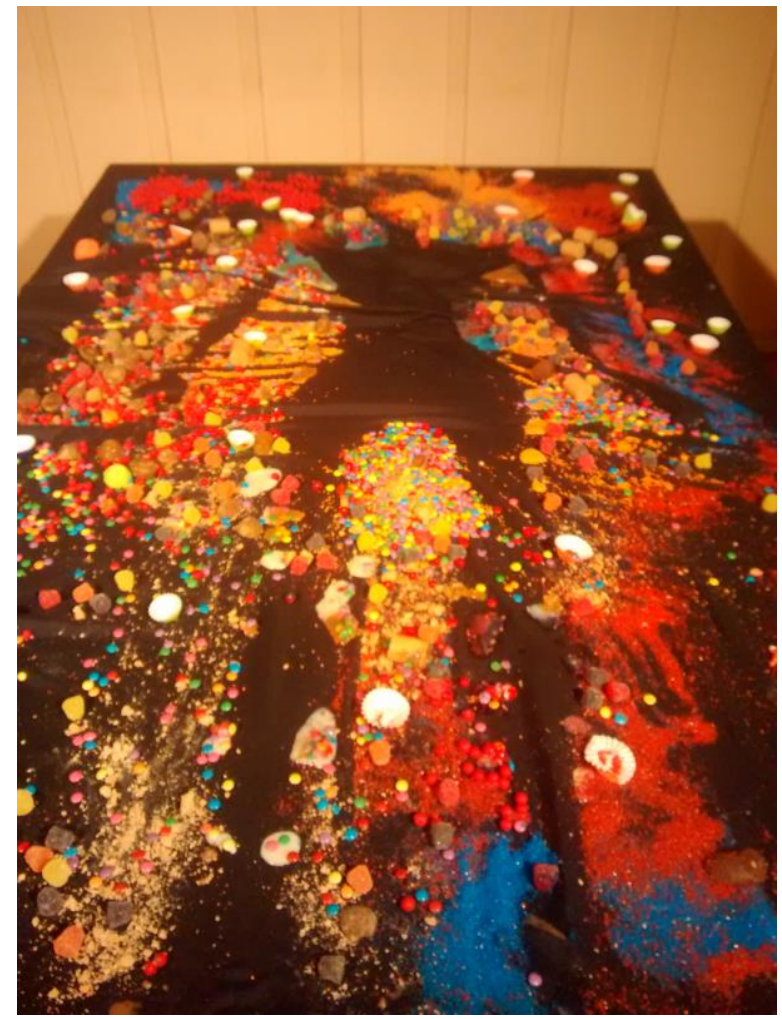

*Foto após o término de Oblação 


\section{Bibliografia}

BLANCHOT, Maurice. L'entretien infinit. Paris: Gallimard, 2009.

BOURCIER, Marie-Hélène. BILDUNGS POST-PORN: notas sobre a proveniência do pós-pornô, para um futuro do feminismo da desobediência sexual. IN: Bagoas. N.11, 2014, pp.15-37.

DELEUZE, Gilles. Critique et clinique. Paris : Les Éditions de Minuit, 1993.

. Nietzsche et la philosophie. Paris : PUF, 2014.

DELEUZE, Gilles; GUATTARI, Félix. Mil Platôs: capitalismo e esquizofrenia. São Paulo: 34, 2008.

FOUCAULT, Michel. Dits et Écrits vol I. Paris: Gallimard, 2001a.

Dits et Écrits vol II. Paris: Gallimard, 2001b.

KAFKA, Franz. A colônia penal. São Paulo: Cia das Letras, 2000.

MAUSS, Marcel. Ensaio sobre a dádiva. IN: Sociologia e antropologia. São Paulo: Cosac Naify, 2003.

MISKOLCI, Richard. Notas sobre os microfascimos nas redes. IN Cult. 3 de março de 2017. Disponível em <https://revistacult.uol.com.br/home/redes-de-ressentimentonotas-sobre-o-microfascismo-nas-redes-sociais/>. Acessado em 26/07/2017.

PELBART, Peter Pál. Estamos em guerra. Texto do site "Outras palavras", publicado em 19/01/2017. Acessado em 21/01/2018. Disponível em <https://outraspalavras.net/ brasil/peter-pal-pelbart-estamos-em-guerra/> 


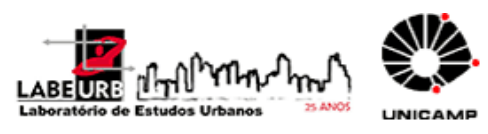

\section{Para citar essa obra:}

GALANTIN, Daniel Verginelli. Sobre as performances Oblação, de Bia Figueiredo, e A outra coleção particular de Stéfano Belo, de Stéfano Belo. In: RUA [online]. no. 24. Volume 1 - p. 37 - 53 - e-ISSN 2179-9911 - junho/2018. Consultada no Portal Labeurb - Revista do Laboratório de Estudos Urbanos do Núcleo de Desenvolvimento da Criatividade.

http://www.labeurb.unicamp.br/rua/

Capa: GALANTIN, Daniel Verginelli

\section{Laboratório de Estudos Urbanos - LABEURB}

Núcleo de Desenvolvimento da Criatividade - NUDECRI

Universidade Estadual de Campinas - UNICAMP

http://www.labeurb.unicamp.br/

\section{Endereço:}

LABEURB - LABORATÓRIO DE ESTUDOS URBANOS

UNICAMP/COCEN / NUDECRI

CAIXA POSTAL 6166

Campinas/SP - Brasil

CEP 13083-892

Fone/ Fax: (19) 3521-7900

Contato: http://www.labeurb.unicamp.br/contato 